\title{
Changing Governance of the World's Forests
}

IFRI Working Paper \#W08I-4

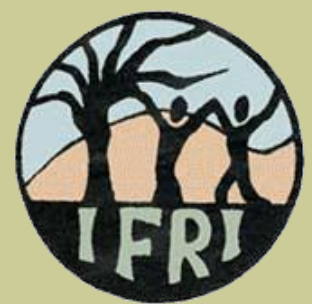

Arun Agrawal

Ashwini Chhatre

Rebecca Hardin

INTERNATIONAL FORESTRY

RESOURCES AND

INSTITUTIONS PROGRAM

School of Natural Resources and Environment

University of Michigan

440 Church Street, MI 48109

Phone: 734-764-9542

Fax: 734-647-5047

http://www.umich.edu/ ifri/ 


\title{
Changing Governance of the World's Forests
}

\author{
Arun Agrawal \\ Natural Resources and Environment \\ University of Michigan \\ Ashwini Chhatre \\ Department of Geography \\ University of Illinois at Urbana-Champaign \\ Rebecca Hardin \\ Department of Anthropology/Natural Resources and Environment \\ University of Michigan
}

May 2008

Revised manuscript prepared for Science Special Issue on "Forests in Flux." 


\title{
Changing Governance of the World's Forests
}

\author{
Abstract \\ Major features of contemporary forest governance include decentralization of forest management, logging \\ concessions in publicly owned commercially valuable forests, and timber certification, primarily in temperate \\ forests. Although a majority of forests continue to be owned formally by governments, the effectiveness of forest \\ governance is increasingly independent of formal ownership. Growing and competing demands for food, biofuels, \\ timber, and environmental services will pose severe challenges to effective forest governance in the future, \\ especially in conjunction with the direct and indirect impacts of climate change. A greater role for community and \\ market actors in forest governance and deeper attention to the factors that lead to effective governance, beyond \\ ownership patterns, is necessary to address future forest governance challenges.
}


Central governments own by far the greater proportion - approximately 86 percent - of the 5.4 billion hectares of the world's forests and wooded areas. Private and "other" (mostly communal) forms of ownership constitute just over 10 percent and below 4 percent of global forests, respectively ( 1 ). There are important regional variations around these averages (Fig.1, based on (1)). Official statistics on forest ownership, however, misrepresent the extent of and changes in forest cover (2). They also misrepresent the nature and changing forms of global forest governance.

Figure 1. Distribution of forest ownership by world regions

\section{Figure 1}
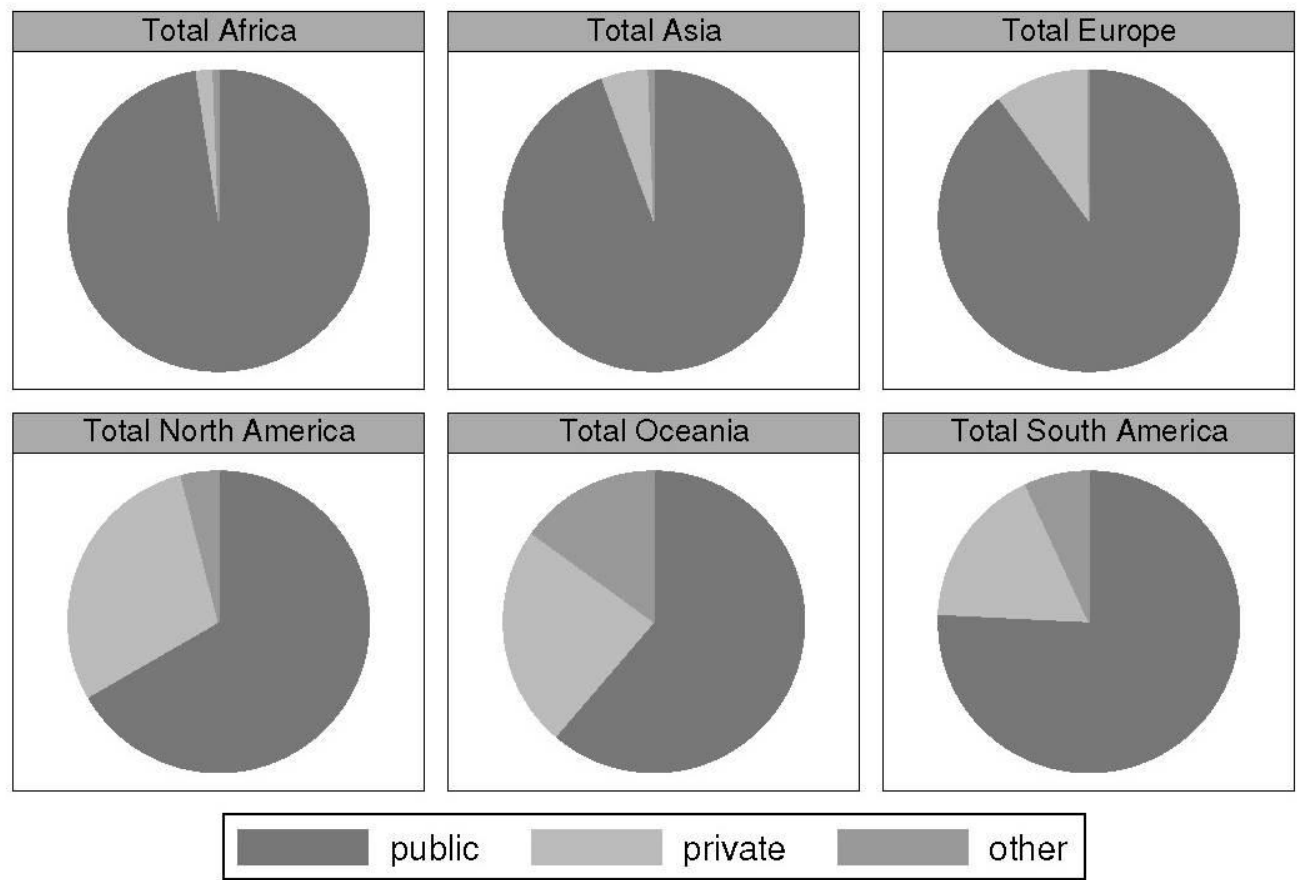

Graphs by World Region 
Effective governance is central to improved forest cover and change outcomes. Changing forest governance today is for the most part a move away from centrally administered, top-down, regulatory policies that characterized much of the nineteenth and twentieth centuries. Many government-owned forests are managed as common property for multiple uses by local communities and community-based organizations (3). Many other forests classified under public ownership are effectively governed as private timber concessions by logging companies (4). Civil society organizations and market incentives increasingly play a role in forest governance through certification processes and changing consumer preferences (5). At the same time, the growth in the number and size of strict protected areas in the latter half of the $20^{\text {th }}$ century has also meant that approximately 6.4 million $\mathrm{km}^{2}$ of publicly owned forests are now under governance regimes that involve stricter restrictions on human use and habitation (6, 7; Fig. S1).

In the $21^{\text {st }}$ century, three important forest governance trends stand out: i) decentralization of management, especially for commercially low-value forests that nonetheless play an important role in the livelihoods of hundreds of millions of rural households in developing countries; ii) the substantial role of logging companies in forest concessions, typically for selective logging in tropical forests; and iii) the growing importance of market-oriented certification efforts, mainly in temperate forests in the developed world.

Decentralization of forestry policies began in the mid to late 1980s, and had become a prominent feature of forest governance by the mid 1990s $(8,9)$. It was impelled in part by infusions of material and technical support from bilateral, multilateral, and private donors who sought better forest governance from recipient countries. These external pressures coincided with domestic demands for a greater recognition of local communities' needs for forest products and role in managing local forests for multiple purposes (10). They also worked in the same direction as the desire of many governments to reduce the financial burden of forest governance in an economic context characterized by significant fiscal and budgetary pressures. An emerging body of scholarly work on local participation, resource institutions, governance, and accountability helped provide some justification for decentralization reforms $(11,12)$. Decentralization reforms in the last two decades have often promoted local, more democratic participation in governance. In tandem with policy advocacy and social movements they have fostered new practices of forest use, sometimes provoking social tensions revolving around claims of indigenous peoples 
within forest zones (10). Overall, local communities and organizations have come to govern close to an additional 200 million hectares of forests compared to the 1980s $(13,14)$.

The private concession model in forest governance has been in existence at least since the imperial trades of the early 1700s, enduring shifts in commodity values, political systems, and changing forest policy frameworks (15). Under concessionary forest governance central governments or forest departments provide logging companies long-term resource extraction rights in commercially valuable forests in exchange for a stream of revenues. Although a variety of logging concessions arrangements also exist in the developed world, they are a dominant form of forest governance in tropical forests in Southeast Asia, parts of the Amazon, and especially in Central and West Africa where at least 75 million hectares of forests are under concession to logging companies (4). Contemporary governance through forest concessions is prompted by demand for logs and timber - often in distant markets, and governments' need for revenues. The limited enforcement of concession agreements in most countries in Southeast Asia and Africa has also meant that legal logging in concessions exists side by side with costly and unsustainable levels of illegal logging (16). The World Bank estimates US\$ 15 billion to be lost to developing countries every year as a result of illegal logging.

Forest certification initiatives emerged in the early 1990s as market instruments in which an independent certification body provides an assurance to consumers that forest product suppliers have conformed to some predetermined criteria of sustainable forest management (17). Certification efforts were launched as a way to improve the sustainability of tropical forest management. Yet they have been used far more broadly in temperate forests - less than 10 percent of 80 million hectares of certified forests in 2000 were in the tropics (18). Certification processes and performance standards are expanding into new regions and niches as a market and civil society response to public concern about deforestation, the organizational strength of international environmental NGOs, and continuing economic globalization (5).

Decentralization, concession, and certification-related trends in forest governance are the result of important social, economic, and political drivers (see Fig. 2). 
Figure 2. Changes in forest governance and their social, economic and political drivers

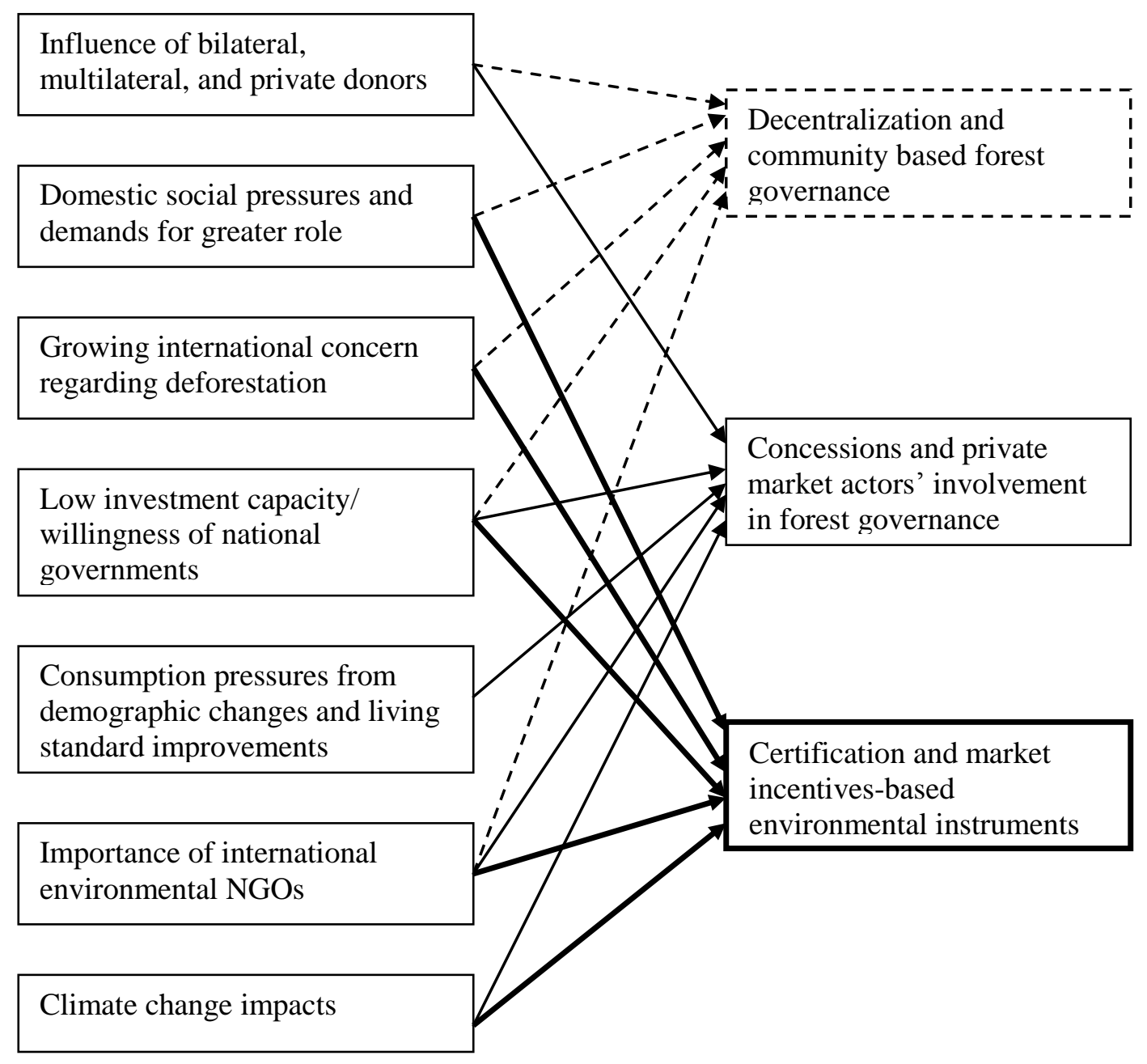


The role of drivers mentioned in Fig. 2 is likely to be reinforced and made more complex by climate change. Existing trends around conversion of forests to biofuel plantations, for example, are likely to affect both biodiversity and the livelihoods of the poor adversely.

In conjunction with competing demands for food and forest products from a growing, and on the average wealthier, global population, climate change impacts will strengthen governance trends especially in the direction of concessions and certification, increase the involvement of market actors in forest governance, and create pressures toward greater formalization as governments seek to take advantage of emerging carbon funds. The intersection of production strategies for food, fuel, and forest products as competition grows for scarce land will inevitably lead to new experiments with governance arrangements at all levels - from the local to the international. It can potentially reverse contemporary trends in favor of the involvement of civil society actors and communities, instead promoting greater privatization. The need for making careful choices in this regard will become especially critical after the next two decades as the joint effects of changes in climate, demographic patterns, and living standards begin to be felt more acutely (19).

The effectiveness of forest governance is only partly explained by who owns forests. At the local level, existing research finds only a limited association between whether forests are under private, public, or common ownership, and changes in forest cover or sustainability of forest management (11). National-level association between forest area under different forms of ownership and changes in forest cover is also relatively weak, especially for public ownership (Spearman's rho for proportion of forests under public ownership and forest cover change $=0.017, \mathrm{p}>|\mathrm{t}|=0.98$, based on data in 1 ). At the regional level, the greatest net declines in forests have occurred in tropical countries. Conversely, net increases in forest cover have occurred primarily in North America and Europe (See Figs. S2 and S3 for illustration). But the relationship between this pattern and forest ownership is limited. Moreover, there is only limited knowledge about the relationships between condition of forests, different forms of forest ownership, and the multiple objectives of forest governance - improvements in income, livelihoods, biodiversity, carbon sequestration, and ecosystem service provision.

The need to look deeper, therefore, into how governance arrangements work is paramount if forest dwellers, users, managers, and policy makers are to make better choices about forest governance at a variety of scales. A very large number of factors influences the effectiveness and outcomes of forest governance $(20,21)$. Among these, more careful definition of user rights and responsibilities in forests, greater participation by those who 
use and depend on forests, downward and outward accountability of decision makers, better monitoring of forest outcomes, stronger enforcement of property rights and governance arrangements, and investments in institutional capacities at local, regional, and national levels have been identified as critically important for more effective forest governance in tropical country contexts.

Broadly speaking, the goal of forest conservation has historically not been met when in conflict with land use changes driven by the demand for food, fuel, and profit. It is necessary to recognize and advocate for better governance of forests more strongly given the importance of forests in meeting basic human needs in the future, making resources available for livelihoods and development, maintaining ecosystems and biodiversity, and addressing climate change mitigation and adaptation goals. Such advocacy must be coupled with financial incentives for developing country governments and a greater governance role for civil society and market actors if forests are to continue to provide benefits to humans well into the future.

Many scholars recognize the central importance of governance in influencing forest outcomes. But the review also shows major gaps in existing knowledge about the history and distribution of forest governance arrangements, and in the understanding of how different features of governance affect outcomes. The challenge of understanding the coupled social and ecological systems (22) that all forest governance represents urgently needs more emphasis and attention than it has received until now. 


\section{References and Notes}

1. Food and Agriculture Organization, "Global Forest Resources Assessment, 2005" (FAO, Rome, 2005).

2. A. Grainger, Proc. Natl. Acad. Sci. U.S.A. 105, 818-823 (2008).

3. T. M. Hayes, World Dev. 34, 2064-2075 (2006).

4. A. Karsenty, "Overview of industrial forest concessions and concession-based industry in Central and West Africa" (CIRAD, Paris, 2007).

5. B. Cashore, F. Gale, E. Meidinger, D. Newsom, “Confronting sustainability: Forest certification in developing and transitioning countries" (Yale University, New Haven, 2006).

6. P. West, J. Igoe, D. Brockington, Ann. Rev. Anthro. 35, 251-277 (2006).

7. K. S. Zimmeer, R. E. Galt, M. V. Buck, Ambio 33, 520-529 (2004).

8. K. P. Andersson, C. C. Gibson, Jour. Pol. Anal. Mgmt. 26, 99 (2007).

9. J. C. Ribot, A. Agrawal, A. Larson, World Dev. 34, 1864-1886 (2006).

10. P. Cronkleton, P. L. Taylor, D. Barry, S. Stone Jovicich, M, Schmink, "Environmental governance and the emergence of forest-based social movements" (CIFOR, Bogor, 2008).

11. T. Dietz, E. Ostrom, P. Stern, Science 302, 1907 (2003).

12. E. Ostrom, Governing the Commons (Cambridge Univ. Press, New York, 1990).

13. A. Molnar, S. J. Scherr, A. Khare, "Who conserves the world's forests?” (Forest Trends, Washington DC, 2004).

14. A. White, A. Martin, "Who owns the world's forests?" (Forest Trends, Washington DC, 2002).

15. R. Hardin, "Concessionary politics in the Congo Basin" (WP \#6, Institutions and Governance Program, World Resources Institute, Washington, DC, 2002).

16. M. Keller et al., Front. Ecol. Environ. 5, 213-216 (2007).

17. E. E. Meidinger, Human Ecol. Rev. 4, 52-54 (1997).

18. Food and Agriculture Organization, "Global Forest Resources Assessment, 2000” (FAO, Rome, 2001).

19. Rights and Resources Initiative, "Transitions in forest tenure and governance: Drivers, projected patterns and implications" (RRI: Washington DC, 2007).

20. A. Agrawal and A. Chhatre, World Dev. 34, 149-166 (2006).

21. E. Ostrom, Proc. Natl. Acad. Sci. U.S.A. 104, 15181-15187 (2007)

22. J. Liu et al., Science 317, 1513 (2007) 
23. The authors thank Bhim Adhikari, Krister Andersson, Daniel Brown, Clark Gibson, Jan Mc Alpine, Elinor Ostrom, Jesse Ribot and two anonymous reviewers for their comments on an earlier draft of the paper. We gratefully acknowledge support from the Ford Foundation and the MacArthur Foundation, and two NSF grants numbered HSD-0527138 and CNH-0709545. 
Figure S1: Growth in protected areas between 1950-2005 (IUCN categories Ia, Ib, and II) (S2)
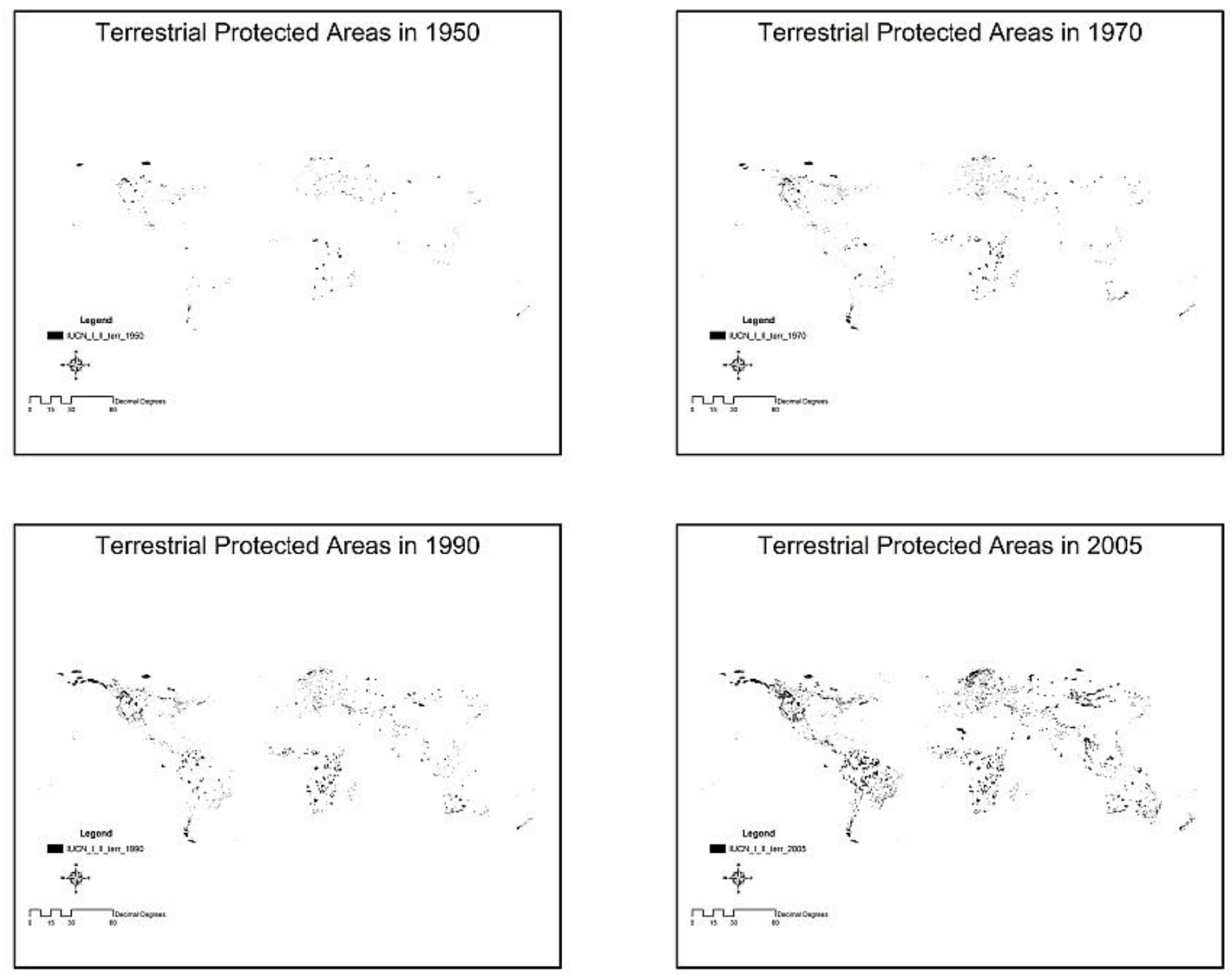
Figure S2: Ownership of forests and other wooded land by country - 2000 (S1)

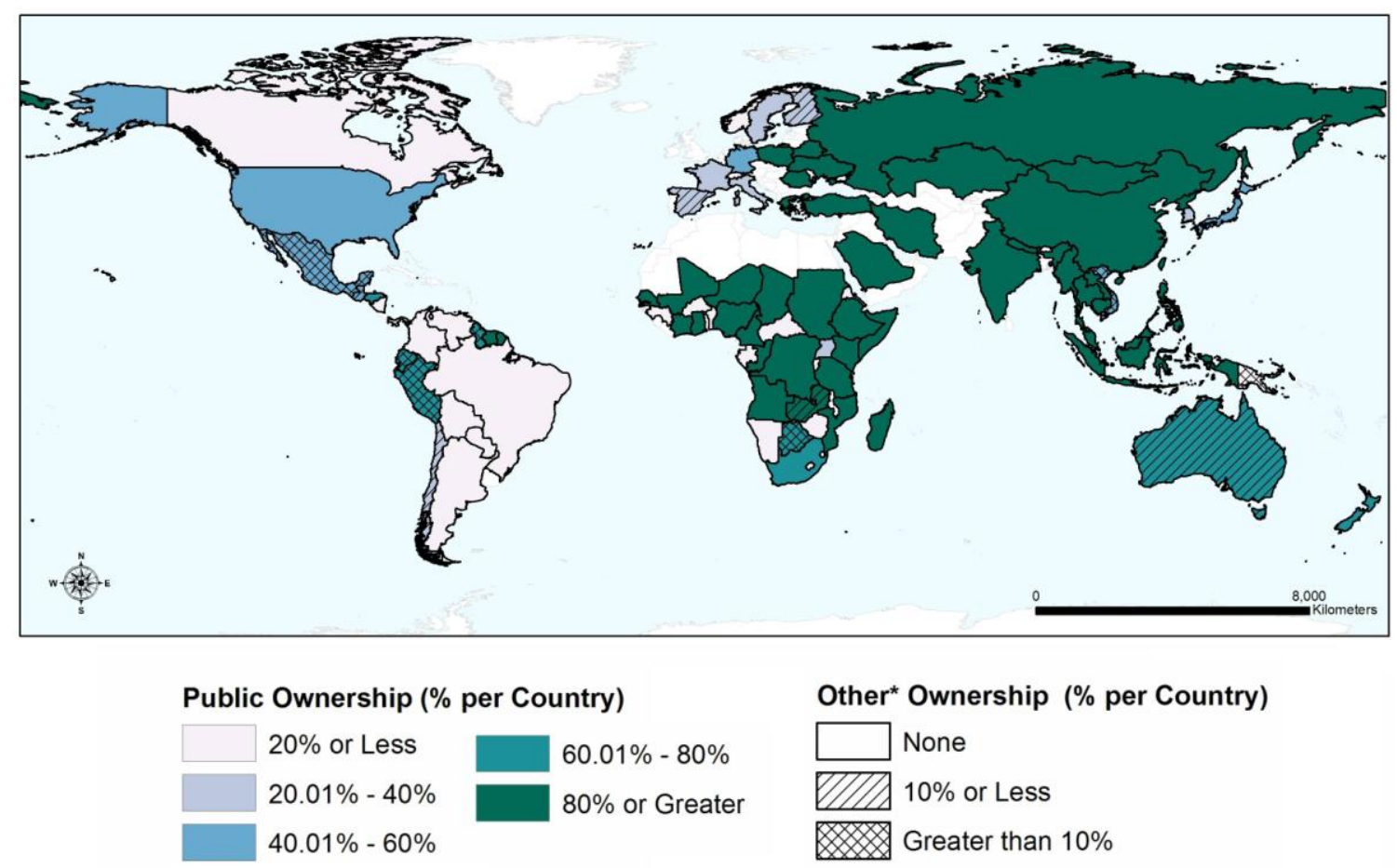

"Other ownership" denotes communal and any other form of ownership than public or private. Only countries with greater than 5 million hectares of forest are depicted on the map. Base Map Source: Countries 2006 ArcWorld Supplement, ESRI ArcGIS 9 Media Kit. 
Figure S3: Change in extent of forest and other wooded land by country between $2000-2005$ (S1)

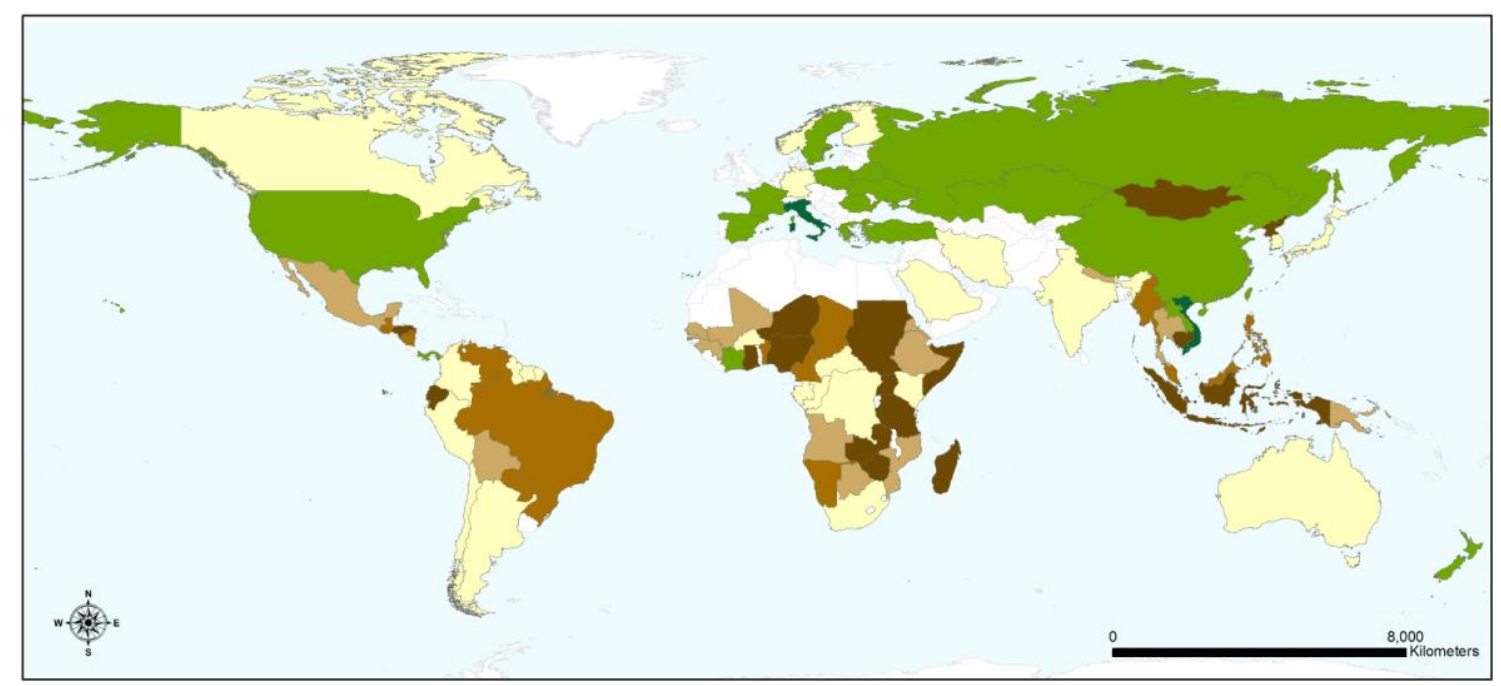

\section{Change in Forest Extent (Percent by Country)}

Reduction in Cover Greater Than $0.05 \%$
Reduction in Cover Between $0.05 \%$ and $0.025 \%$

Reduction in Cover Between $0.01 \%$ and $0 \%$

Increase in Cover Between $0 \%$ and $0.05 \%$

Increase in Cover Greater than $0.05 \%$

Only countries with greater than 5 million hectares of forest are depicted on the map. Base Map Source: Countries 2006 ArcWorld Supplement, ESRI ArcGIS 9 Media Kit. 


\section{References and Notes}

S1. Food and Agriculture Organization, "Global Forest Resources Assessment, 2005" (FAO, Rome, 2005)

S2. United Nations Environment Program and World Conservation and Monitoring Center, "World Database on Protected Areas (UNEP-WCMC, Cambridge (U.K.), 2007)

S3. We thank Rachel Kornak for her assistance in preparing Figures S2 and S3. 